\title{
Bazı Fenolik Bileşiklerin Yoğunluk Fonksiyonu Yöntemi ile Antioksidan Aktivitelerinin Tayin Edilmesi
}

\author{
Vildan ENISOĞLU ATALAY ${ }^{* 1}$, Hatice OCAK ${ }^{2}$ \\ 1Üsküdar Üniversitesi, Mühendislik ve Doğa Bilimleri Fakültesi, Biyomühendislik Bölümü, 34662, İstanbul \\ ${ }^{1}$ (ORCID: https://orcid.org/0000-0002-9830-9158) \\ 2İstanbul Protein Araştırma Geliştirme ve İnovasyon ve Araștırma Merkezi (PROMER), İstanbul \\ ${ }^{2}$ (ORCID: https://orcid.org/0000-0003-0866-5923)
}

(Alınış / Received: 02.07.2018, Kabul / Accepted: 29.01.2019, Online Yayınlanma / Published Online: 15.03.2019)

\author{
Anahtar Kelimeler \\ B3LYP, \\ Antioksidan aktivite, \\ HAT, \\ SET-PT, \\ SPLET, \\ DFT
}

\begin{abstract}
Özet: Oksidatif stresin başta kanser olmak üzere ateroskleroz, hipertansiyon ve kardiyovasküler hastalıklar gibi pek çok hastalığın patogenezinde rol oynadığı çeşitli araştırmalar sonucunda görülmüștür. Fenolik bileşikler ise insan sağlığı bakımından antioksidan fonksiyonları ile ön plana çıkan maddelerdir. Fenolik antioksidanların serbest radikaller ile reaksiyona girme eğilimi antioksidan aktiviteyi tanımlamaktadır. Bu çalışmada 10 adet fenolik bileşik gaz etanol ve su fazlarında Spartan 14 programı ile DFT//B3LYP metodu ve 6-31+G(d) temel seti ile HAT, SET-PT ve SPLET oksidasyon mekanizmaları gaz, su ve etanol fazlarında modellenmiştir. Elde edilen verilere göre BDE, ETE, PA, IP, PDE ve $\Delta$ (Еномо-Eцuмо) değerleri hesaplanarak antioksidan aktiviteleri sıralanmıştır. Yapılan hesaplamalardan elde edilen tüm sonuçlar değerlendirildiğinde bileşik 1 olarak tanımlanan 2-hexadecyl-2,5,7,8-tetramethylchroman-6-ol molekülünün antioksidan aktivitesi çalışılan yöntem ve fazlarda en yüksek olarak bulunmuştur.
\end{abstract}

\section{Determination of Antioxidant Activities by Density Function Method of Some Phenolic Compounds}

\section{Keywords}

B3LYP,

Antioxidant activity,

HAT,

SET-PT,

SPLET,

DFT

\begin{abstract}
Oxidative stress is implicated in various disease pathologies including cancer, atherosclerosis, hypertension, and cardiovascular disease. Phenolic compounds have antioxidant functions in terms of human health. The tendency of phenolic antioxidants to react with free radicals identifies their antioxidant activity. In this study, HAT, SET-PT and SPLET oxidation mechanisms were modeled in the gas, water and ethanol phases with the DFT // B3LYP method and $6-31+G(d)$ basis set with 10 phenolic compounds using Spartan 14. Antioxidant activities were ranked by calculated BDE, ETE, PA, IP, PDE and $\Delta$ (Еномо-Ецuмо) values according to the obtained data. The antioxidant activity of 2-hexadecyl2,5,7,8-tetramethylchroman-6-ol, identified as compound 1 , was found to be highest in the methods and phases studied when all the results obtained from the calculations made were evaluated.
\end{abstract}

\section{Giriş}

Oksidatif stres, antioksidanların yetersizliği sonucu oksidatif dengenin bozulması sonucu meydana gelen hücre ve doku hasarı veya hücre ölümleri olarak tanımlanmaktadır [1-3]. Serbest radikaller gida oksidasyonunda önemli bir rol oynar ve olması gerekenden çok artış gösterdiğinde meydana gelen oksidatif stres kardiyovasküler hastalıklar, kanser, solunum ve boşaltım bozuklukları, diabet, yaşlanma gibi birçok rahatsızlığa sebep olmaktadırlar [4, 5].
İnsan sağlığı bakımından antioksidan fonksiyonları ile ön plana çlkan maddeler $\mathrm{E}$ ve $\mathrm{C}$ vitaminleri, karotenoidler ve fenolik maddelerdir. Serbest radikaller ile reaksiyona girerek uzaklaştıran fenolik antioksidanlarda hidroksil grubunun yeri, sübstitüe grupların özelliği ve hidrojen bağı oluşumu gibi aktiviteyi etkileyen birçok faktör yapı-aktivite iliş̧ileri (SAR) ile bulunmuştur [6]. Fenolik maddeler aromatik hidrokarbon yapısında bir veya daha fazla hidroksil grubu içeren oldukça önemli bir madde grubudur [7]. Teorik bir parametre olan ve fenolik 
antioksidandan $\mathrm{H}$ atomu koparılmasindan sonra üretilen serbest radikal arasındaki oluşum isısı farkı $(\Delta \mathrm{H})$, antioksidanların aktivitesini ölçmek için iyi bir indeks olarak ortaya çlkmıștır [8]. Öte taraftan literatürde antioksidan aktivite tayininde kullanılan üç ana antioksidan mekanizma vardır: hidrojen atomu transfer (HAT), tek elektron ve proton transfer (SET-PT) ve siralı proton kaybı elektron transferi(SPLET) mekanizmaları [9].

\section{HAT mekanizması}

HAT mekanizması, oksidatif zincir reaksiyonunu kırmak için antioksidan molekülün homolitik $\mathrm{O}-\mathrm{H}$ bağ bölünmesiyle beraber bir $\mathrm{H}$ atomu ile birleştiği ve antioksidan radikalinin tek adımda oluştuğu ve Bağ Ayrışma Enerji (BDE)'nin hesaplandı̆̆ı (Denk. 1) mekanizmadır. BDE, HAT mekanizmasına ilișkin önemli bir sayısal parametredir ve ilgili hidroksil grubunun stabilitesini karakterize eder, düşük BDE değerine sahip olan bağın stabilitesi düşüktür ve kolayca kırılabileceğinden oldukça güçlü bir antioksidatif etki gösterir [10].

$\mathrm{R} \cdot+$ AntiOx:H $\rightarrow \mathrm{RH}+$ AntiOx

(HAT Mek.)

$\mathrm{BDE}=H(\mathrm{ArO} \cdot)+H(\mathrm{H} \cdot)-H(\mathrm{ArOH}$

\section{SET-PT mekanizması}

İki basamakta gerçekleșen SET mekanizmada birinci adımda bir katyonik radikal ara ürün oluşması ve serbest radikal bileşiğinin anyonik forma geçmesinin ardından, 2. adımda anyonik formdaki serbest radikal antioksidan molekülünden bir $\mathrm{H}$ atomu alarak nötralize olur. Bir fenolik bileşiğin elektron bağışlama yeteneği, tüm molekül üzerinde genişletilmiş bir elektronik delokalizasyon ile ilgilidir. Yüksek bir $\pi-$ delokalizasyon derecesine sahip olan bir fenolik bileşik daha aktiftir. SET mekanizma antioksidasyon olayının enerjetik olarak açılklanmasında İyonizasyon Potansiyeli (IP)'ni (Denk. 2) ve katyon radikalinin deprotonasyonuna ait Proton Ayrıșma Enerjisi (PDE)'ni (Denk. 3) kullanarak önemli bir enerji değerinin hesaplanmasından sorumludur.

$\mathrm{R}+$ AntiOx:H $\rightarrow \mathrm{R}:^{-}+$AntiOx $\mathrm{H}^{+} \rightarrow \mathrm{R}: \mathrm{H}+$ AntiOx (SET Mek.)

$\mathrm{IP}=H\left(\mathrm{ArOH}^{+} \cdot\right)+H\left(\mathrm{e}^{-}\right)-H(\mathrm{ArOH})$

$\mathrm{PDE}=H(\mathrm{ArO} \cdot)+H\left(\mathrm{H}^{+}\right)-H\left(\mathrm{ArOH}^{+}\right)$

\section{SPLET mekanizması}

Üç adımda gerçekleşen SPLET mekanizmasına göre birinci adımda oluşan AntiOx- anyonun oluşumu sözkonusu bileşikteki $\mathrm{OH}^{-}$grubunun Proton Afinitesi (PA, Denk.4) ile ilişkilidir. Elektron Transfer Enerjisi (ETE, Denk.5) tarafından yönetilen ikinci adımda AntiOx-radikal formu oluşurken, son adımda serbest radikalin nötralize olmuş formu elde edilir. Yüksek antioksidatif aktivite düşük PA ve ETE değerleri ile ilişkili olduğu belirtilmektedir.

$$
\begin{aligned}
& \text { AntiOx:H } \rightarrow \text { AntiOx- }+\mathrm{H}^{+} \quad \text { (Proton ilgisi ile ilişkili) } \\
& \text { AntiOx }+\mathrm{R}^{-} \rightarrow \text { AntiOx }+\mathrm{R}^{-}(\overline{\mathrm{e}} \text { transfer enerjisi ile ilişkili) } \\
& \mathrm{R}^{-}+\mathrm{H}^{+} \rightarrow \mathrm{RH} \\
& \mathrm{PA}=\left(\mathrm{ArO}^{-}\right)+H\left(\mathrm{H}^{+}\right)-(\text {ArOH }) \\
& \text { ETE }=H(\text { ArO })+H\left(\mathrm{e}^{-}\right)-H\left(\mathrm{ArO}^{-}\right)
\end{aligned}
$$

Antioksidan özellikleri tayin etmekte kullanılan diğer önemli kriterler ise moleküler tanımlayıcı olarak ifade edilen elektronegatiflik $(\chi)$, elektron afinitesi (EA), kimyasal sertlik $(\eta)$ ve elektrofilisite indeksi $(\omega)$ parametreleridir. Kimyasal sertlik, yük transferine karşı direncin bir ölçüsüdür; elektronegatiflik ise, elektronları kimyasal bir bağ içinde çekme eğiliminin bir ölçüsüdür. Bir verici ve bir alıcı arasındaki maksimum elektron akışı, atomlar arasındaki bağlanma enerjisinin ayrıșması tarafından yönetilir ve faktör elektrofilisite indeksi ile belirlenir. $\mathrm{Bu}$ çalışmada $\chi, \eta, S$ ve $\omega$ değerleri Koopman'ın teorisine göre nötral moleküllerin HOMO-LUMO

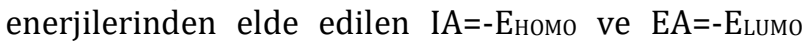
değerleri Denk. 6-9'da kullanılarak elde edilmiştir [11].

$$
\begin{array}{ll}
X=-\mu \approx(\mathrm{IP}+\mathrm{EA}) / 2 & \text { (6) } \mathrm{S} \approx 1 /(2 \eta) \\
\eta \approx(\mathrm{IP}-\mathrm{EA}) / 2 & \text { (8) } \omega \approx \mu^{2} / 2 \eta
\end{array}
$$

Bu çalışmada 10 farklı fenolik antioksidan bileşiğinin (Şekil 1) antioksidan aktivite sıralamalarını oluşturmak için literatürde önerilen üç temel mekanizma (HAT, SET-PT ve SPLET) DFT//B3LYP metodu 6-31+G(d) temel kümesi ile modellenmiş ve moleküler tanımlayıcılar elde edilerek moleküllerin antioksidan aktivite sıralaması yapılmıștır.

\section{Materyal ve Metot}

Söz konusu çalışmada literatürde [6] yapısal olarak antioksidan aktiviteye sahip olduğu öne sürülen fenolik antioksidan bileşiklerin HAT, SET-PT ve SPLET mekanizmalar için tek nokta enerji hesaplamaları yapılarak BDE, IP, PDE, PA ve ETE

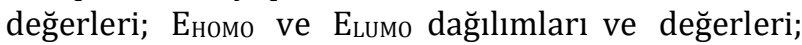
antioksidan aktivite için önemli bir veri olan $\chi, E A, \eta$ ve $\omega$ değerleri paket programlar kullanılarak elde edilmiştir.

Bileşiklerin konformer taramaları yarı ampirik PM6 yöntemi [12, 13] ile Spartan'14 [14] programinda yapılmıştır. Elde edilen en kararlı konformerlerin geometri optimizasyonları GaussView5 [15] görselleştirme programı kullanılarak yoğunluk fonksiyonu teoremi (DFT) [16] B3LYP metodu ve 6- 


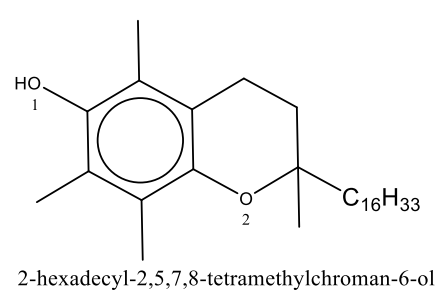

(1)

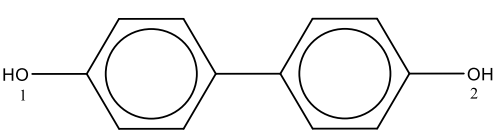

4-allyl-2,6-dimethoxyphenol

(3)

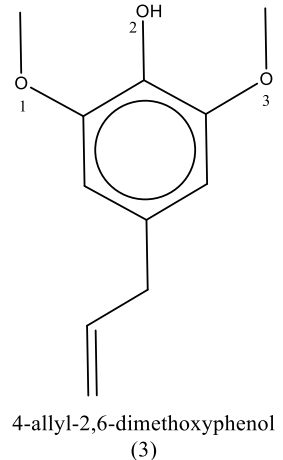

[1,1'-biphenyl]-4,4'-dio

(2)

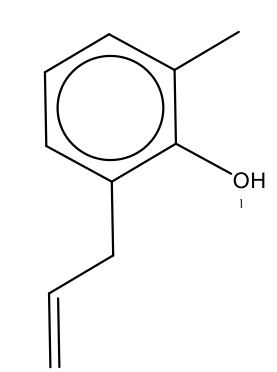

2-allyl-6-methylphenol

(6)

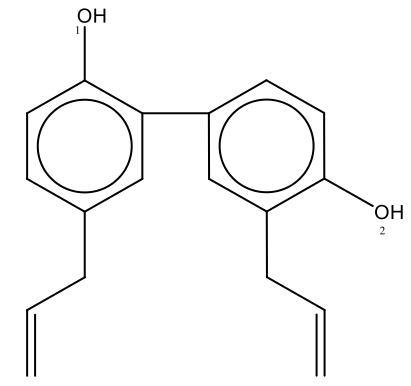

(7)

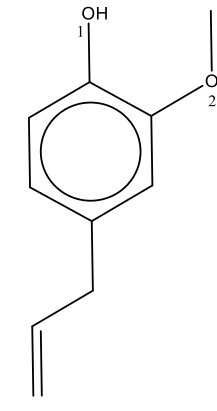

(4)

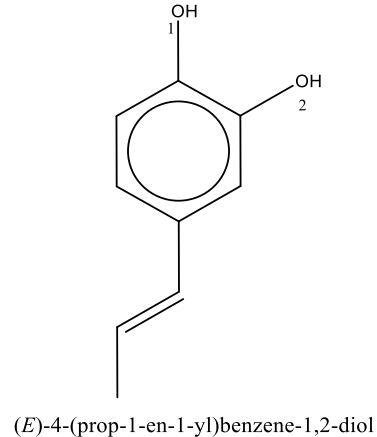

$(5)$

Şekil 1. İncelenen (1):2-hexadecyl-2,5,7,8 tetramethylchroman-6-ol; (2):[1,1'-biphenyl]-4,4'-diol; (3): 4-allyl-2,6dimethoxyphenol; (4): 4-allyl-2-methoxyphenol; (5): (E)-4-(prop-1-en-1-yl)benzene-1,2-diol; (6): 2-allyl-6-methylphenol; (7): 3',5-diallyl-[1,1'-biphenyl]-2,4'-diol; (8): 5,5'-diallyl-[1,1'-biphenyl]-2,2'-diol; (9): 4-ethylphenol; (10): 2-methoxyphenol fenolik antioksidan bileșiklerinin 2D yapıları (ChemDraw 15.0) ve $\mathrm{OH}$ numaralandırılmaları

31+G(d) temel seti ile Gaussian09 [17] programında gerçekleştirilmiştir. Fenolik bileşiklerin antioksidatif özelliklerini araştırmak için yaygın ve etkili bir yöntem olduğu için, DFT hesaplaması uygulanmıştır [10]. Optimize yapilar HAT, SET-PT ve SPLET mekanizmaları ve zamana bağlı tek nokta enerji (TDSP) hesabından elde edilen Еномо ve ELumo değerleri DFT//B3LYP/6-31+G(d) [18, 19] metodu ile gaz, etanol ve su ortamlarında Spartan'14 programı kullanılarak hesaplanmış ve HOMO-LUMO dağılımları görüntülenmiştir. Aynı metot ile hesaplanan $H\left(\mathrm{H}^{+}\right)$, $H\left(\mathrm{e}^{-}\right)$ve $H(\mathrm{H} \cdot)$ değerleri gaz, etanol ve su fazlarında hesaplanmiştır.

\section{Bulgular ve Tartışma}

İncelenen fenolik antioksidan bileşiklerin HAT ve SPLET mekanizmaların gaz, etanol ve su ortamlarinda DFT//B3LYP/6-31+G(d) metodu ile modellenmesinde elde edilen BDE ve ETE değerleri Tablo 1'de listelenmiștir. Tablo 1 incelendiğinde literatürde Zheng ve arkadaşları tarafından yapılan çalışmada da olduğu gibi polar faza geçildiğinde BDE değerleri daha düşük bulunmuştur. Çalışılan moleküller arasında en düşük BDE değeri bileşik 1 için de gaz, etanol ve su fazlarının hepsinde olmak üzere sırasıyla $345.0385 \mathrm{Kjmol}^{-1}, 331.4765 \mathrm{Kjmol}^{-1}$, $328.3524 \mathrm{Kjmol}^{-1}$ olarak hesaplanmıștır. İncelenen bileşiklerin BDE değerlerine göre antioksidan aktiviteleri gaz fazında 1>5-0H2 $>3>2>9>6>4>7$ $\mathrm{OH} 1>5-\mathrm{OH} 1>10>7-\mathrm{OH} 2>8 \mathrm{OH} 2>8-\mathrm{OH} 1$, etanol ve su fazinda $\quad \mathbf{1}>\mathbf{5}-\mathbf{0 H} 2>3>5-\mathrm{OH} 1>4>9>10>2>7-0 \mathrm{H} 1>8$ $\mathrm{OH} 2>8-\mathrm{OH} 1>6>7-0 \mathrm{H} 2$ olarak gözlenmiștir. Elde edilen BDE sıralamasındaki ilk üç değer çalıșılan tüm ortamlarda aynı bulunurken polar fazlardaki sıralama tamamen aynı olarak tespit edilmiştir. Bileșik 1, 3 ve 5'in yapısı incelendiğinde 1 numaralı bileșiğin $\mathrm{OH}$ grubunun bağlı olduğu benzen halkasında o- ve p- pozisyonlarında 3 adet $-\mathrm{CH}_{3}$ grubunu olması ve bu grubun indüktif ve mezomerik olarak e- verme özelliği bisiklik yapıda bulunan ilgili bileșiğin antioksidan özelliğinin azaltmasına karşılık bisiklik formu tarafından önemli oranda desteklendiğini göstermektedir. Öte taraftan bileşik 5'te $\mathrm{OH} 2$ grubu iki tarafından indüktif olarak e- çeken sübstitüentlere daha yakın komşu olması sebebi ile OH1'e göre daha kuvvetli antioksidan karakter taşımaktadır. Bileşik 4 ile yapısal olarak çok benzeyen bileşik 3'e baktığımızda ise $\mathrm{OH}$ grubunun opozisyonlarında iki adet $\mathrm{e}^{-}$çeken grupların varlığ indüktif olarak yapıya antioksidan karakter kazandırmış olması $\mathrm{OH}$ grubunun etrafındaki sübstitüe grupların sayısının ve karakterinin önemini vurgulamıştır. SPLET mekanizmanın modellenmesinden elde edilen gaz, etanol ve su fazlarındaki ETE değerleri aşağıda Tablo 1'de verilmiștir. 
Tablo 1. DFT//B3LYP/6-31+G(d) yöntemi ile hesaplanan O-H bağı için BDE ve ETE değerleri (Kjmol-1)

\begin{tabular}{lllllll}
\hline & \multicolumn{3}{c}{ BDE } & \multicolumn{3}{c}{ ETE } \\
\hline bileșik & gaz & etanol & su & gaz & etanol & su \\
\hline 1 & $\mathbf{3 4 5 . 0 3 8 5}$ & $\mathbf{3 3 1 . 4 7 6 5}$ & $\mathbf{3 2 8 . 3 5 2 4}$ & -1041.8475 & $\mathbf{- 8 1 0 . 4 8 6 9}$ & $\mathbf{- 7 9 5 . 2 2 3 0}$ \\
2 & 382.5955 & 371.4951 & 367.8633 & -1005.6594 & -769.0483 & $-\mathbf{7 5 2 . 5 0 6 6}$ \\
3 & 368.5388 & 354.9616 & 351.6868 & $\mathbf{- 1 0 4 2 . 1 9 6 7}$ & -803.6944 & -786.2677 \\
4 & 390.7222 & 367.5235 & 362.8509 & -1030.1007 & -779.4527 & -760.6617 \\
5-OH1 & 393.2500 & 366.7697 & 361.2985 & -1021.2804 & -766.8300 & -746.7200 \\
5-OH2 & 351.8763 & 343.7816 & 340.1529 & -1001.3100 & -772.9036 & -757.7424 \\
6 & 389.6158 & 379.5055 & 376.8750 & -1011.2754 & -766.2099 & -750.6727 \\
7-OH1 & 392.0620 & 375.7547 & 372.4878 & -1003.9114 & -768.3849 & -751.4504 \\
7-OH2 & 395.3394 & 387.3589 & 385.0598 & -974.6084 & -757.8146 & -742.2008 \\
8-OH1 & 398.8615 & 379.9786 & 376.8606 & -977.2489 & -756.4034 & -740.0975 \\
8-OH2 & 398.7654 & 379.8941 & 376.7713 & -977.1350 & -756.2485 & -739.9436 \\
9 & 382.6551 & 370.7566 & 367.1092 & -1022.3500 & -769.8932 & -752.8663 \\
10 & 395.2942 & 371.7267 & 367.1470 & -1029.3562 & -772.9501 & -754.3164 \\
\hline
\end{tabular}

Tablo 1 incelendiğinde polar fazlarda literatür ile uyumlu olarak ETE değerlerinin yükseldiği gözlemlenmiștir [19]. En düșük ETE değeri gaz fazında bileșik 3 için $\left(-1042.1967 \mathrm{Kjmol}^{-1}\right)$, polar fazlarda ise bileșik 1 için elde edilmiștir (etanol ve su fazları için sırasıyla $-810.4869 \mathrm{Kjmol}^{-1},-795.2230$ Kjmol-1 $^{-1}$. Düşük ETE değerleri yüksek antioksidan etkiyi temsil etmeleri nedeni ile araștırılan bileşiklerin arasında yapılan incelemede gaz fazında $3>1>4>10>9>5-0 H 1>6>2>7 \quad$ H $1>5-0 H 2>8-0 H 1>8-$ $\mathrm{OH} 2>7-\mathrm{OH} 2$, etanol fazında $1>3>4>10>5$ $\mathrm{OH} 2>9>2>7-\mathrm{OH} 1>5-\mathrm{OH} 1>6>7-\mathrm{OH} 2>8-\mathrm{OH} 1>8-\mathrm{OH} 2$

ve su fazinda $1>3>4>5-\mathrm{OH} 2>10>9>2>7-\mathrm{OH} 1>6>5-$ $\mathrm{OH} 1>7-\mathrm{OH} 2>8-\mathrm{OH} 1>8-\mathrm{OH} 2$ şeklinde sıralanmıştır. Elde edilen sıralamaya bakıldığında ilk üç bileșik aynı çıkmıştır. Ancak yaklaşık olarak $0.35 \mathrm{Kjmol}^{-1}{ }^{1} l u ̈ k ~ b i r$ fark ile gaz fazı ve polar fazlarda elde edilen sıralamada bileşik 1 ve bileşik 3 farklı sıralamada bulunmuștur.

SET-PT mekanizmasının ikinci adımından elde edilen PDE değerleri Tablo 2'de listelenmiştir. Tablo 2 incelendiğinde PDE değerleri polar fazlara geçildiğinde önemli ölçüde düștüğü gözlenmiștir. Gaz fazında en düşük PDE değeri bileşik 9 (926.0960 $\mathrm{Kjmol}^{-1}$ ) için elde edilirken polar fazlara gelince bileşik 8'in $\mathrm{OH} 2$ (etanol ve su fazları için sırasıyla $693.4811 \mathrm{Kjmol}^{-1}, 680.9179 \mathrm{Kjmol}^{-1}$ ) grubu için elde edilmiştir. SET-PT mekanizması için gaz fazında PDE değerleri sıralaması $9>6>5-\mathrm{OH} 2>10>3>4>8-\mathrm{OH} 2>8-$ $\mathrm{OH} 1>2>5-\mathrm{OH} 1>7-\mathrm{OH} 1>7-\mathrm{OH} 2>1$; etanol fazında 80H2>8-0H1 $>6>9>5-0 H 2>7-0 H 1>3>1>10>4>7-$ $\mathrm{OH} 2>2>5-\mathrm{OH} 1$ ve su fazında 8-0H2 $>\mathbf{8 - 0 H} 1>\mathbf{6}>\mathbf{9}>\mathbf{5}$ OH2 $>1>3>7-0 H 1>10>4>7-0 H 2>2>5-0 H 1 \quad$ olarak gözlenmiştir.

SPLET mekanizmadan elde edilen PA değerleri gaz, etanol ve su fazları için aşağıda Tablo 2'de listelenmiştir. Tablo 2 incelendiğinde etanol fazındaki PA değerlerinin gaz fazındaki değerlerden yaklaşık $600 \mathrm{Kjmol}^{-1}$, su fazındaki PA değerlerinin ise gaz fazındaki değerlerden yaklaşık $630 \mathrm{Kjmol}^{-1}$ düşük olduğu saptanmıştır.

Bileşik 5'in 2-OH grubunun diğer moleküllerin $\mathrm{OH}$ gruplarının PA değerlerinden daha küçük olduğu dolayısıyla 2-0- anyon oluşumunun diğer anyon oluşumlarından daha kolay olabileceği anlamına gelir. SPLET mekanizmasında PA'ların değerine göre en yüksek antioksidan etki gösteren bileşik 5'tir. Bileșiklerin antioksidan sıralaması gaz fazında 5OH2 $>7-0 H 2>8-0 H 2>8-0 H 1>1>2-0 H 1>2-0 H 2>7-$

$\mathrm{OH} 1>6>9>3>5-\mathrm{OH} 1>4>10$; etanol fazında 5-0H2 $>5$ OH1 $>8-0 H 2>8-0 H 1>2>9>1>7-0 H 1>10>7-0 H 2>6>4$ $>3$ ve su fazında 5-0H2 $>\mathbf{5 - 0 H 1}>\mathbf{8 - 0 H 2}>8-0 H 1$ $>9>2>10>4>1>7-0 \mathrm{H} 1>7-0 \mathrm{H} 2>6>3 \quad$ olarak saptanmıştır.

Tablo 2. DFT//B3LYP/6-31+G(d) yöntemi ile hesaplanan PDE ve PA değerleri (Kjmol-1)

\begin{tabular}{lcccccc}
\hline \multicolumn{3}{c}{ PDE } & \multicolumn{3}{c}{ PA } \\
\hline bileşik & gaz & etanol & su & gaz & etanol & su \\
\hline 1 & 992.5241 & 701.8745 & 688.8196 & 1487.8559 & 822.8962 & 792.4835 \\
2 & 981.9690 & 719.3073 & 706.5898 & 1489.2248 & 821.4763 & 789.2780 \\
3 & 972.1880 & 701.8916 & 688.9664 & 1511.7054 & 839.5888 & 806.8626 \\
4 & 972.7979 & 709.3029 & 695.6616 & 1521.7928 & 827.9090 & 792.4208 \\
5 -OH1 & 986.7172 & 723.1282 & 708.9939 & 1515.5003 & 814.5327 & 776.9266 \\
5 -OH2 & 945.3436 & 700.1401 & 687.8484 & $\mathbf{1 4 5 4 . 1 5 6 3}$ & $\mathbf{7 9 7 . 6 1 8 1}$ & $\mathbf{7 6 6 . 8 0 3 5}$ \\
6 & 939.0327 & 694.1742 & 683.0697 & 1501.8611 & 826.6483 & 796.4559 \\
$7-0 H 1$ & 988.6530 & 701.8853 & 689.1165 & 1496.9433 & 825.0725 & 792.8464 \\
$7-0 H 2$ & 991.9304 & 713.4895 & 701.6885 & 1470.9177 & 826.1064 & 796.1687 \\
$8-0 H 1$ & 976.8911 & 693.5656 & 681.0072 & 1477.0803 & 817.3149 & 785.8662 \\
$8-0 H 2$ & 976.7950 & $\mathbf{6 9 3 . 4 8 1 1}$ & $\mathbf{6 8 0 . 9 1 7 9}$ & 1476.8703 & 817.0754 & 785.6231 \\
9 & $\mathbf{9 2 6 . 0 9 6 0}$ & 698.4380 & 687.1317 & 1505.9750 & 821.5826 & 788.8837 \\
10 & 952.2757 & $\mathbf{7 0 8 . 6 2 3 9}$ & 695.4632 & 1525.6203 & 825.6096 & 790.3716 \\
\hline
\end{tabular}


$\mathrm{Bu}$ çalışmada incelenen fenolik antioksidan türevi bileşiklerin SET-PT mekanizması üzerinden hesaplanan IP değerleri Tablo 3'te listelenmiştir. Tablo 3 incelendiğinde elektronun en kolay koparıldı̆̆ bileşik 1 olarak gözlenmiştir. Gaz fazındaki siralama 1>3>2>7>5>4>8>10>6>9 şeklinde iken etanol ve su fazlarında $1>5>2>3>4>10>9>7>6>8$ şeklinde tespit edilmiştir.

Tablo 3. DFT//B3LYP/6-31+G(d) yöntemi ile hesaplanan IP değerleri $\left(\mathrm{Kjmol}^{-1}\right)$

\begin{tabular}{lccc}
\hline bileșik & gaz & etanol & su \\
\hline 1 & $\mathbf{- 5 4 6 . 5 1 5 7}$ & $\mathbf{- 6 8 9 . 4 6 5 2}$ & $\mathbf{- 6 9 1 . 5 5 9 1}$ \\
2 & -498.4037 & -666.8794 & -669.8183 \\
3 & -502.6793 & -665.9972 & -668.3714 \\
4 & -481.1058 & -660.8465 & -663.9026 \\
5 & -492.4973 & -675.4256 & -678.7873 \\
6 & -448.4470 & -633.7358 & -637.2866 \\
7 & -495.6211 & -645.1977 & -647.7206 \\
8 & -477.0597 & -632.6541 & -635.2384 \\
9 & -442.4711 & -646.7486 & -651.1143 \\
10 & -456.0115 & -655.9644 & -659.4080 \\
\hline
\end{tabular}

Antioksidan aktivitenin önemli bir kriteri olan

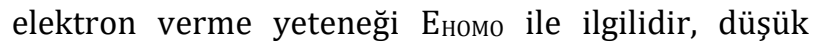
Еномо proton vermekteki zayıf yetenekleri, yüksek

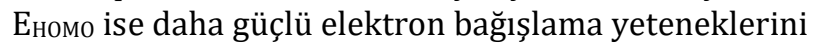
gösterir [20]. Diğer önemli bir parametrede düșük Elumo değeridir. Еномо-Elumo arasındaki bandgap değeri ne kadar düşük olursa e- bir üst orbital seviyesine daha kolay geçeceği için daha kolay iyonize hale geçmeyi ve yüksek antioksidan aktiviteyi temsil eder [21, 22]. Aşağıda Tablo 4'te
DFT//B3LYP/6-31+G(d) yöntemi ile elde edilen gaz, etanol ve su fazlarındaki $\mathrm{E}_{\text {номо-E }} \mathrm{E}_{\text {Luмо, bandgap ve }}$ moleküler tanımlayıcı parametreleri listelenmiștir. Çalıșılan 10 adet fenol türevi antioksidan bileşik için gaz, etanol ve su fazlarında sirasıyla $-5.35 \mathrm{eV},-5.66 \mathrm{eV}$ ve $-5.7 \mathrm{eV}$ değerleri ile elde edilen en yüksek Еном değerine sahip bileşik 1 olarak saptanmıştır. ЕномоELumo arasındaki bandgap'e bakıldığında da en düșük değer çalışılan tüm ortamlarda yine bileşik 1 için elde edilmiştir. Düşük bandgap enerjisinin molekülün antioksidan özellik taşıdığı anlamına gelmesi çalışılan bileșiklerin antioksidan aktivite sıralamaları gaz fazında $1>7>5>2>8>3>4>6>9>10$ şeklinde iken etanol ve su fazlarında $1>5>2>8>7>4>3>9>6>10$ şeklinde sıralanmıştır. Diğer taraftan DFT//B3LYP/6-31+G(d) yöntemi ile gaz, etanol ve su fazlarında hesaplanan ve Tablo 4 'te listelenen $\chi, \eta, \mu$, $S$ ve $\omega$ moleküler tanımlayıcı değerleri literatürdeki farklı antioksidan moleküllerin yoğunluk fonksiyonu teorisi ile elde edilen değerleri ile kiyaslandığında bileşiklerin elektron verici karakter taşıdıkları tespit edilmiştir [23, 24], ki bu özellik antioksidan aktivitelerinin bir göstergesidir.

Tablo 5-7'te fenolik antioksidan türevi bileşiklerin DFT//B3LYP/6-31+G(d) yöntemi ile elde edilen HOMO-LUMO dağılımları verilmiștir. HOMO-LUMO görüntüleri incelendiğinde HOMO orbitallerinin fenolik halkada yoğunlaştığı görülürken LUMO orbitallerinin özellikle sübstitüe gruplar üzerinde moleküle yayıldığı görülmüştür.

Tablo 4. DFT/6-31+G(d) metodu ile gaz fazında hesaplanan moleküler tanımlayıcılar: Eномо (eV), ELuмo (eV), bandgap (eV)

\begin{tabular}{|c|c|c|c|c|c|c|c|c|c|c|c|}
\hline \multirow{2}{*}{\multicolumn{2}{|c|}{$\begin{array}{l}\text { moleküler } \\
\text { tanımlayıcılar }\end{array}$}} & \multicolumn{10}{|c|}{ bilessik } \\
\hline & & 1 & 2 & 3 & 4 & 5 & 6 & 7 & 8 & 9 & 10 \\
\hline \multirow{8}{*}{$\begin{array}{l}\text { స్ } \\
\text { న్ }\end{array}$} & Еномо & -5.35 & -5.78 & -5.57 & -5.74 & -5.68 & -6.01 & -5.9 & -6.16 & -6 & -5.84 \\
\hline & $\mathrm{E}_{\text {LUMO }}$ & -0.85 & -0.67 & -0.23 & -0.39 & -0.61 & -0.65 & -0.94 & -1.02 & -0.44 & -0.19 \\
\hline & bandgap & -4.5 & -5.11 & -5.34 & -5.35 & -5.07 & -5.36 & -4.96 & -5.14 & -5.56 & -5.65 \\
\hline & $\chi$ & 3.1 & 3.23 & 2.9 & 3.07 & 3.15 & 3.33 & 3.42 & 3.59 & 3.22 & 3.02 \\
\hline & $\hat{\mu}$ & -3.1 & -3.23 & -2.9 & -3.07 & -3.15 & -3.33 & -3.42 & -3.59 & -3.22 & -3.02 \\
\hline & $\eta$ & 2.25 & 2.56 & 2.67 & 2.68 & 2.54 & 2.68 & 2.48 & 2.57 & 2.78 & 2.83 \\
\hline & S & 0.22 & 0.2 & 0.19 & 0.19 & 0.2 & 0.19 & 0.2 & 0.19 & 0.18 & 0.18 \\
\hline & $\omega$ & 2.14 & 2.04 & 1.58 & 1.76 & 1.95 & 2.07 & 2.36 & 2.51 & 1.87 & 1.61 \\
\hline \multirow{9}{*}{ 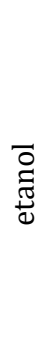 } & moleküler & \multicolumn{10}{|c|}{ bileșik } \\
\hline & tanımlayıcılar & 1 & 2 & 3 & 4 & 5 & 6 & 7 & 8 & 9 & 10 \\
\hline & Еномо & -5.66 & -5.9 & -5.88 & -5.97 & -5.84 & -6.28 & -6.12 & -6.26 & -6.14 & -6.05 \\
\hline & ELUMO & -1.1 & -0.8 & -0.37 & -0.56 & -0.78 & -0.73 & -0.92 & -1.1 & -0.6 & -0.4 \\
\hline & bandgap & -4.56 & -5.1 & -5.51 & -5.41 & -5.06 & -5.55 & -5.2 & -5.16 & -5.54 & -5.65 \\
\hline & $x$ & 3.38 & 3.35 & 3.13 & 3.27 & 3.31 & 3.51 & 3.52 & 3.68 & 3.37 & 3.23 \\
\hline & $\hat{\mu}$ & -3.38 & -3.35 & -3.13 & -3.27 & -3.31 & -3.51 & -3.52 & -3.68 & -3.37 & -3.23 \\
\hline & $\eta$ & 2.28 & 2.55 & 2.76 & 2.71 & 2.53 & 2.78 & 2.6 & 2.58 & 2.77 & 2.83 \\
\hline & S & 0.22 & 0.2 & 0.18 & 0.18 & 0.2 & 0.18 & 0.19 & 0.19 & 0.18 & 0.18 \\
\hline & $\omega$ & 2.51 & 2.2 & 1.77 & 1.97 & 2.17 & 2.03 & 2.38 & 2.62 & 2.05 & 1.84 \\
\hline \multirow{10}{*}{ ตี } & moleküler & \multicolumn{10}{|c|}{ bileşik } \\
\hline & tanımlayıcılar & 1 & 2 & 3 & 4 & 5 & 6 & 7 & 8 & 9 & 10 \\
\hline & Еномо & -5.7 & -5.92 & -5.93 & -6.01 & -5.87 & -6.31 & -6.16 & -6.3 & -6.17 & -6.09 \\
\hline & ELUMo & -1.13 & -0.81 & -0.4 & -0.59 & -0.81 & -0.75 & -0.94 & -1.12 & -0.62 & -0.43 \\
\hline & bandgap & -4.57 & -5.11 & -5.53 & -5.42 & -5.06 & -5.56 & -5.22 & -5.18 & -5.55 & -5.66 \\
\hline & $\chi$ & 3.42 & 3.37 & 3.17 & 3.3 & 3.34 & 3.53 & 3.55 & 3.71 & 3.4 & 3.26 \\
\hline & $\hat{\mu}$ & -3.42 & -3.37 & -3.17 & -3.3 & -3.34 & -3.53 & -3.55 & -3.71 & -3.4 & -3.26 \\
\hline & $\eta$ & 2.29 & 2.56 & 2.77 & 2.71 & 2.53 & 2.78 & 2.61 & 2.59 & 2.78 & 2.83 \\
\hline & S & 0.22 & 0.2 & 0.18 & 0.18 & 0.2 & 0.18 & 0.19 & 0.19 & 0.18 & 0.18 \\
\hline & $\omega$ & 2.55 & 2.22 & 1.81 & 2.01 & 2.2 & 2.24 & 2.41 & 2.66 & 2.08 & 1.88 \\
\hline
\end{tabular}


Tablo 5. HOMO-LUMO Gaz Fazı görüntüleri

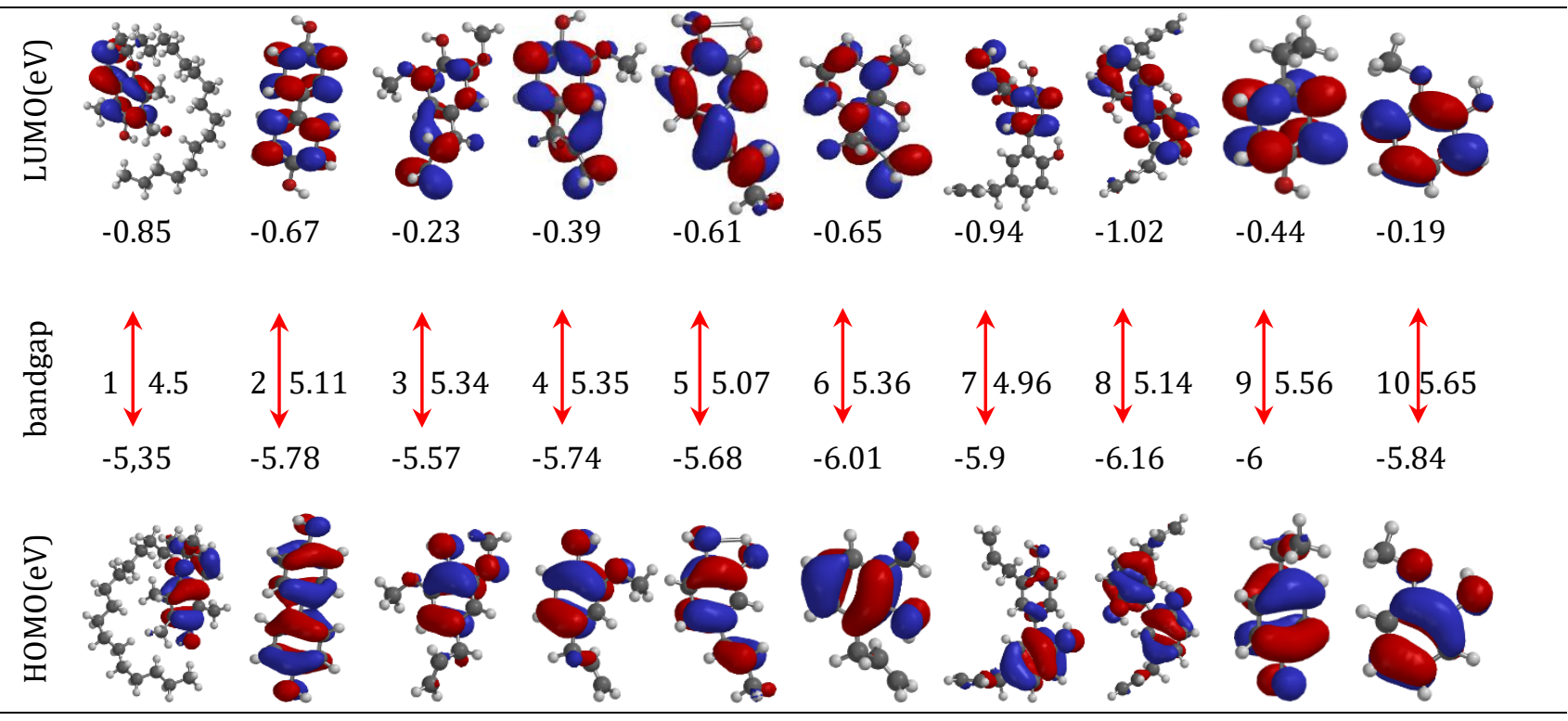

Tablo 6. HOMO-LUMO Etanol Fazı görüntüleri

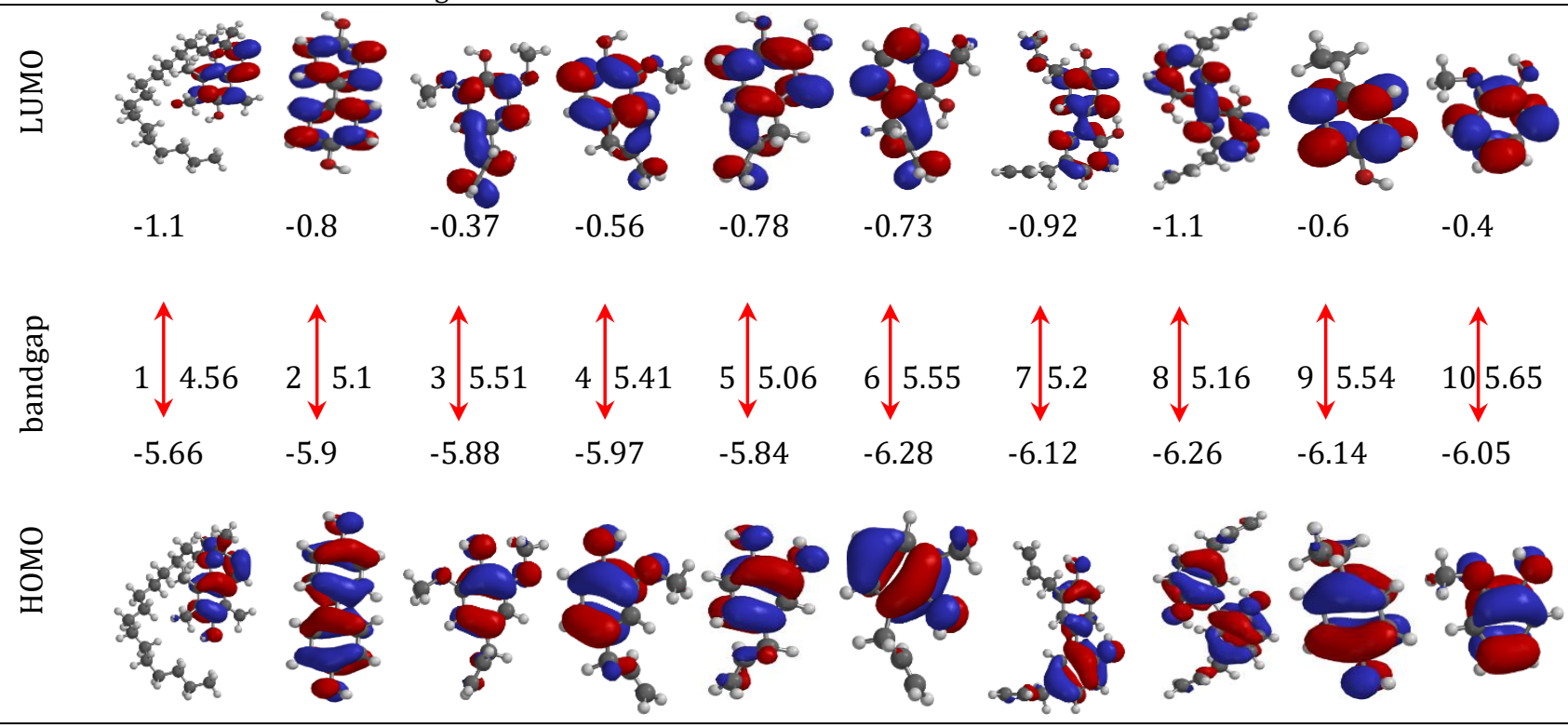

Tablo 7. HOMO-LUMO Su Fazı Görüntüleri

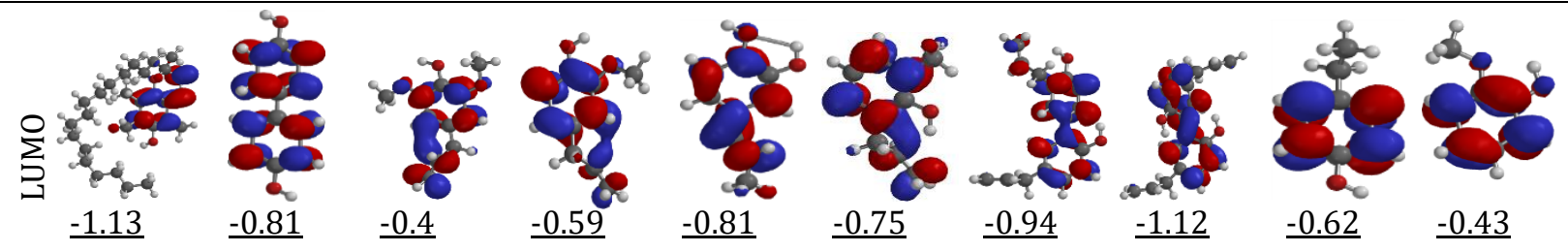

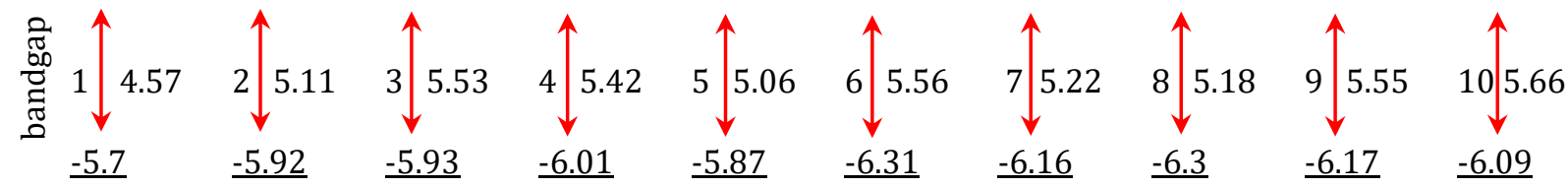

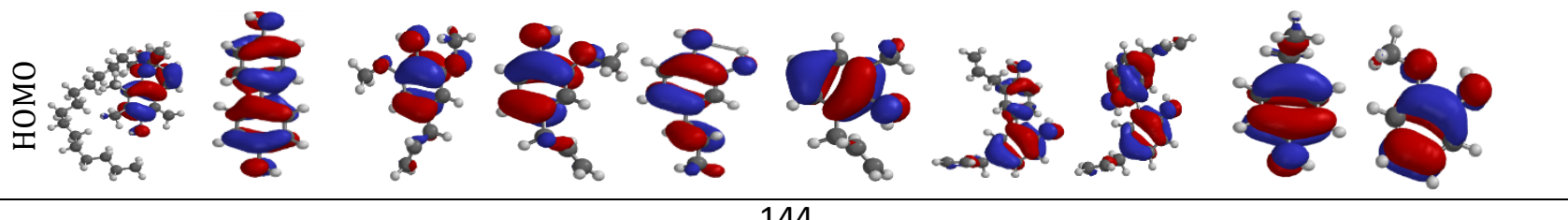




\section{Sonuç}

$\mathrm{Bu}$ çalışmada Spartan 14 programı ve DFT//B3LYP/6-31+G(d) yöntemi ile 10 adet fenolik bileşiğin gaz etanol ve su fazlarında HAT, SET-PT ve SPLET mekanizmaları modellendi. Elde edilen verilere göre BDE, ETE, PA, IP, PDE ve $\Delta$ (Еномо-ELuмо) değerleri hesaplanarak antioksidan aktiviteleri sıralanmıştır. HAT mekanizmadan elde edilen BDE değerlerindeki ilk üç fenolik antioksidan aktivite çalışılan tüm fazlarda 1>5-OH2>3 olarak gözlenmiştir. SPLET mekanizmanın modellenmesinden elde edilen ETE değerlerine bağlı siralamada ise gaz fazında $3>1>4$, etanol ve su fazında 1>3>4 şeklinde iken PA değerlerine bağlı antioksidan aktivite sıralaması gaz fazında 5-OH2 $>7$ $\mathrm{OH} 2>8-\mathrm{OH} 2$, etanol ve fazında $5-\mathrm{OH} 2>5-\mathrm{OH} 1>8-\mathrm{OH} 2$ olarak saptanmıştır. SET-PT mekanizmasından elde edilen PDE değerlerine bağlı antioksidan aktivite siralamasinda 9>6>5-0H2; etanol ve su fazında 8 $\mathrm{OH} 2>8-\mathrm{OH} 1>6$ olarak gözlenirken IP değerlerinden elde edilen gaz fazındaki sıralama $1>3>2$ şeklinde iken etanol ve su fazlarında $1>5>2$ şeklinde tespit edilmiştir. Bir diğer önemli parametre olan $\Delta$ (Еномо-

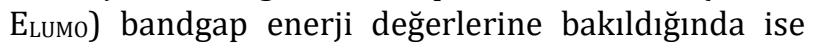
antioksidan aktivite siralamaları gaz fazında $1>7>5$ şeklinde iken etanol ve su fazında $1>5>2$ șeklindedir. Elde edilen tüm sonuçlar değerlendirildiğinde bileşik 1 olarak tanımlanan 2-hexadecyl-2,5,7,8tetramethylchroman-6-ol molekülünün antioksidan aktivitesi çalışılan yöntem ve fazlarda en yüksek olarak bulunmuştur.

Yazarlar bu çalışma ile ilgili herhangi bir çıkar çatışması olmadığını beyan ederler.

\section{Teşekkür}

Yazarlar bilgisayar kaynağı ve yazılım desteği nedeni ile Marmara Üniversitesi Fen-Edebiyat Fakültesi'ne ve Safiye Sağ Erdem'e teşekkür ederler.

\section{Kaynakça}

[1] Özcan, O., Erdal, H., Çakırca, G., Yönden, Z. 2015. Oksidatif Stres ve Hücre İçi Lipit, Protein ve DNA Yapıları Üzerine Etkileri. Journal of Clinical and Experimental Investigations, 6 (2015) 331-336.

[2] Reed, D.J. 1995. Toxicity of Oxygen in Molecular And Cellular Mechanisms of Toxicity. CRC Press, 35-68, Boca Raton- USA.

[3] Younes, M. 1999. Free Radicals and Reactive Oxygen Species, in Toxicology, 'By H. Marguardt, Mechanisms of Antioxidant and Pro-Oxidant Effects of Lipoic Acid in the Diabetic and Nondiabetic Kidney'. Kidney International, 67 (1999), 1371 - 1380.

[4] Berlett, B.S., Stadtman, ER. 1997. Protein Oxidation in Aging, Disease and Oxidative Stress.
The Journal of Biological Chemistry, 272 (1997): 20313-6.

[5] Şahin, D.Y., Elbasan, Z., Gür, M., Türkoğlu, C., Özaltun, B., Sümbül, Z., Çaylı, M. 2012. Relationship Between Oxidative Stress Markers and Cardiac Syndrome X. Journal of Clinical and Experimental Investigations, 3 (2012): 174-180.

[6] Zhang, H.Y. 1999. Theoretical Elucidation of Structure-Activity Relationships of Flavonoid Antioxidants, Science in China (series B) 42 (1999), 106-112.

[7] Shahidi, F., Naczk, M., 1995. Food Phenolics; Technomic Publishing:Lancaster, PA,

[8] Zhang, H. Y. 1998. Selection of Theoretical Parameter Characterizing Scavenging Activity of Antioxidants on Free Radicals, J. Am. Oil Chem. Soc. 75 (1998), 1705-1709.

[9] Lu, L., Qiang, M., Li, F., Zhang, H., Zhang, S., 2014. Theoretical Investigation on the Antioxidative Activity of Anthocyanidins: A DFT/B3LYP Study. Dyes And Pigments, 103(2014), 175-182.

[10] Nenadis, N., Sigalas, M. P. 2011. A DFT Study on the Radical Scavenging Potential of Selected Natural 3',4'-Dihydroxy Aurones. Food Research International, 44 (2011), 114-120.

[11] Urbaniak, A., Molski, M., Szelag, M., 2012. Quantum-Chemical Calculations of the Antioxidant Properties of Trans-P-Coumaric Acid and Trans-Sinapinic Acid. Computational Methods in Science And Technology, 18 (2012), 117-128.

[12] Stewart, J. J. P. 2008. Application of the PM6 method to modeling the solid state, J Mol Model. 14 (2008): 499-535

[13] Stewart, J. J. P. 2009. Application of the PM6 method to modeling proteins, J Mol Model. 15, 7(2009), 765-805

[14] Spartan 14v112 (2013) Wavefunction, Inc., Irvine.

[15] Dennington R, Keith T, Millam J. GaussView, Version 5, Semichem Inc., Shawnee Mission KS, 2009.

[16] Hehre, W. J. 2003. A Guide to Molecular Mechanics and Quantum Chemical Calculations, Wavefunction, Inc., Irvine, CA.

[17] Frisch, M. J. “Gaussian 09”, Gaussian, Inc, 2009. Version 6.

[18] Axel, D. B. 1993. A new mixing of Hartree-Fock and local density-functional theories. The Journal of Chemical Physics 98(1993), 1372.

[19] Petersson, G. A., Bennett, A., Tensfeldt, T. G., AlLaham, M. A., Shirley, W. A., Mantzaris, J. 1988. A complete basis set model chemistry. I. The total energies of closed-shell atoms and hydrides of 
the first-row atoms, J. Chem. Phys., 89 (1988), 2193-218.

[20] Zheng, Y.Z., Deng, G., Liang, Q., Chen, D.F., Guo, R., Lai, R.C. 2017. Antioxidant Activity of Quercetin and Its Glucosides From Propolis: A Theoretical Study. Scientific Reports, 7(2017), 7543.

[21] Weirong, C., Yong, C., Liangliang, X., Hong, Z., Chunyuan, H. 2014. Characterization and density functional theory study of the antioxidant activity of quercetin and its sugar-containing analogues, Eur Food Res Technol, 238 (2014), 121-128.

[22] Al-Majedy, Y. K., Al-Amiery, A. A., Kadhum, A. H., Mohamad, A. B. 2016. Antioxidant Activities of 4-
Methylumbelliferone Derivatives, PLoS One. 11 (2016), 5.

[23] Praveena, R., Sadasivam, K., Kumaresan, R., Deepha, V, Sivakumar R. 2013. Experimental and DFT studies on the antioxidant activity of a C-glycoside from Rhynchosia capitata, Spectrochimica Acta Part A: Molecular and Biomolecular Spectroscopy, 103 (2013), 442452.

[24] Praveena, R., Sadasivam, K., Kumaresan, R., Deepha, V, Sivakumar R., Zheng, Y. Z., Deng G., Liang, Q., Chen, D., Guo, R., Rong-Cai, L., 2013, Antioxidant Activity of Quercetin and Its Glucosides from Propolis: A Theoretical Study, Scientific Reports, 7(2013), 7543. 